\title{
Energy Storage Capacity Expansion of Microgrids for a Long-Term
}

\author{
Dr. Bindhu V,
}

Professor and Head,

Department of Electronics and Communication Engineering,

PPG Institute of Technology,

Villankurichi Saravanampatti P.O,

Coimbatore, India.

\section{Dr. G. Ranganathan,}

Head of the department,

Department of Electronics \& Communication Engineering,

Gnanamani College of Technology,

Namakkal, India.

\begin{abstract}
In this paper, we examine the microgrids and the long-term dynamic capacity expansion planning in their architecture. Many resources contribute towards the supply to microgrid such as energy, micro gas turbine, solar and wind storage system. Moreover the electric vehicle charging stations use these microgrids as a source of electricity. The electric vehicles that are used in charging stations are based on vehicle-to-grid wherein it is possible to regulate the charging rate and time and to transmit energy to the microgrid. Hence, these charging stations are found to be present in generating unit or flexible load. In the microgrid, the capacity expansion planning is initiated to expand the capacity of battery, wind turbine, solar and micro turbine energy storage system. We have elaborated a 6-year planning horizon, targeting a long term plan through capacity expansion. On the other hand, we have also conducted a short term plan simultaneously to improve the hourly operation of electric vehicle charging station, energy and micro turbine storage system. An expansion of about $200 \%$ on wind system is used such that expansion cost is about $53 \%$ and incorporation of further resources will increase it by $58 \%$ in terms of cost.
\end{abstract}

Keywords: Multi stage capacity expansion, microgrid, electric vehicle charging station, dynamic capacity expansion planning 


\section{Introduction}

To address load growth in electrical networks, network expansion planning is one of the optimal methods. This method of expansion is applicable to distribution parts, transmission and generation of the electrical grids. In this planning of network expansion, the components, lines and energy resources are either reinforced or expanded to ensure balance of the load growth, in the future. The planning is set with the prospective of a long-term implementation within the time frame of 5 to 20 years [1]. Here, either new generating technologies are installed or the existing generating units of the system undergo expansion. This issue determines installation time, operation pattern, technology and site of the new generating systems that take into consideration a number of functions such as environmental costs, reliability, operational cost, maintenance cost and investment cost [2]. Depending on economic, technical and security constraints of the system, the optimization programming is handled [3]. However, the major challenge that is faced during this expansion would be the role of optimal long-term and short-term operation, electric vehicles, risk assessment, electricity trade, mutual effect of renewable energy integration [4], environmental impacts, demand side management programs [5], energy storage systems, natural and power gas systems [6] and its integration with transmission networks. It is also possible to integrate energy storage systems and generation expansion. The use of storage technologies will improve the energy usage by days or hours and it will in turn decrease the planning cost efficiency [7].

As far as expansion planning is concerned, different storage technologies are examined and researched [8]. Based on the prediction of load growth, the transmission expansion planning will also be based on reinforcing existing lines and installing new transmission lines. Taking into consideration the economic constraints reliability and security it is possible to decrease investment cost on new lines in the network [9]. However the primary challenges that are faced during this expansion will fall under either of these categories electric vehicles, risk assessment, electricity market trades, demand side management programs, energy storage systems and renewable energy integration. The use of energy storage system has a positive impact on the proposed methodology and a significant decrease in investment is observed [10]. On peak loading is provided by the storage devices 
Journal of Electrical Engineering and Automation (EEA) (2021)

Vol.03/ No.01

Pages: 55-64

https://www.irojournals.com/iroeea

DOI: https://doi.org/10.36548/jeea.2021.1.006

that will also reduce system requirement when you lines are installed. In places where distribution network lines [11] are installed or reinforced, distribution network expansion planning is incorporated. The proposed topology is maintained as radial since it uses distribution goods [12] that are radial for transmission expansion planning. In general, distribution grids are interconnected with demand response programs, microgrids, energy storage systems and distributed generation [13]. This type of distribution will positively improve the efficiency of the system.

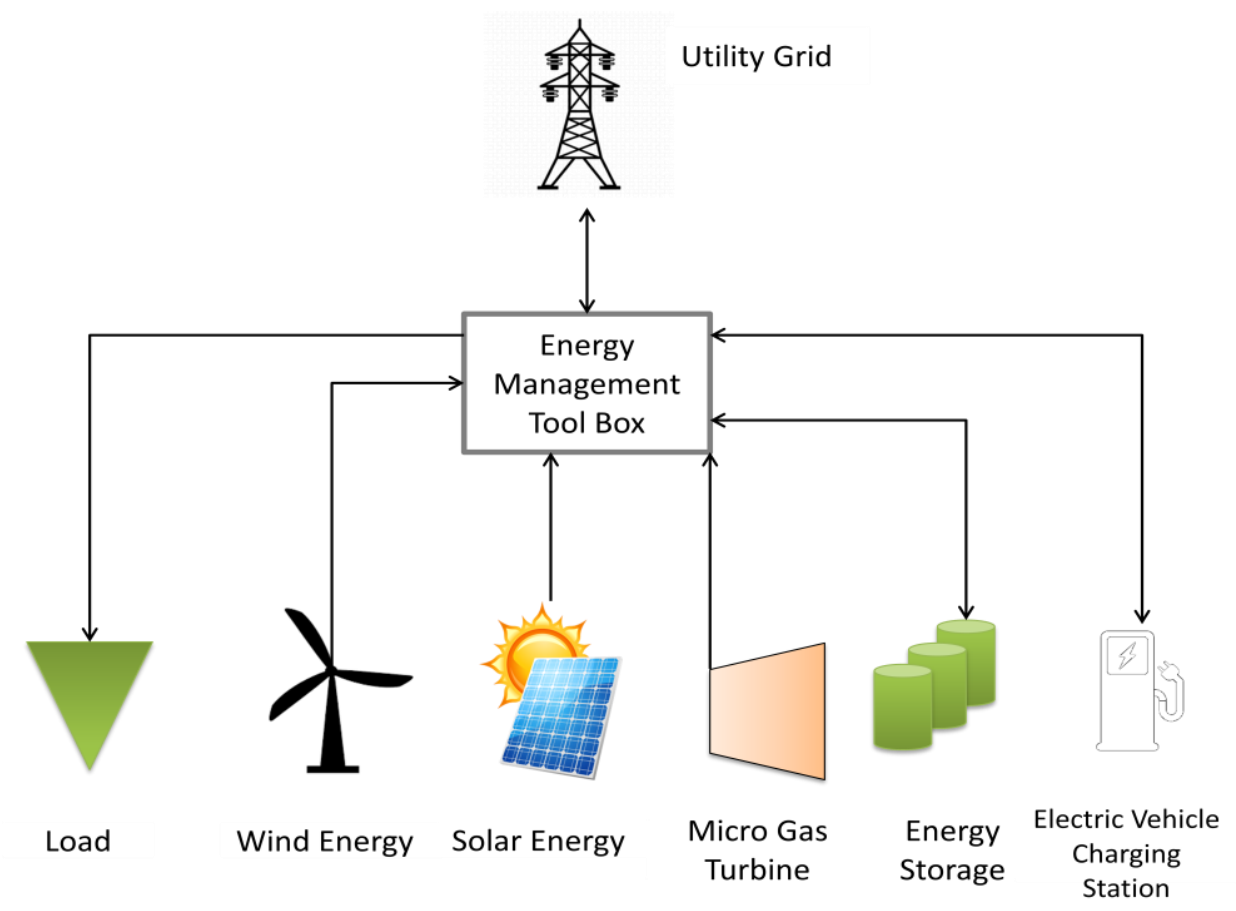

Fig.1. Microgrid Connection

The proposed work shows a novel capacity expansion planning in microgrid using multiple energy resources. The major highlights are as follows:

- Regulating the discharging rate, discharging time, charging rate and charging time of the electric vehicles to optimize the expansion cost.

- Determining the optimal time for operating the electric vehicle charging station.

- Taking into consideration the uncertainty of loads and energy resources 
- Taking into consideration, the operation costs, maintenance and investment in battery energy storage system, wind turbine, solar panels and micro turbine.

\section{Proposed Methodology}

Fig.1 shows a microgrid that supplies the load demand that uses local capacity resources. However, as the demand increases with the years, it is not possible for the microgrid to meet the demand. Hence, there is need for expanding the capacity resources of the microgrid. To find the technology, setting, time and size of new capacity resources, the capacity expansion planning is to be performed. It is essential to expand the microgrid based on the demand with respect to the years of prediction using micro gas turbine, solar, wind and energy storage systems. Fig. 2 shows a brief outline of the proposed model in the form of a flowchart. There are two plans that are used in this capacity expansion methodology namely short-term optimization and long-term optimization programming. They are merged to be applicable on a mixed integer linear programming that reduces the maintenance, operational and investment costs. Interfacing inverters are used to integrate and control the grid when distributed energy resources are concerned. The use of inverters will cause an effect on operation, control strategies and protection schemes of a distribution grid and need to be updated accordingly. Though the resources and line capacity of microgrids are less than electric power system, using it with an expansion model will be applicable to large-scale electrical networks. The energy storage system in the microgrids forms an inseparable component and has many economic and technical advantages. Fig. 2 shows a flowchart of the proposed work.

There are two types of hybrid storages namely long-term and short-term hybrids. Compressed air-super capacity combination is long-term while the battery-flywheel hybrid is said to be short-term. In electric vehicles, the charging facility plays a crucial part in improving the lifetime of the battery as well as the performance of the vehicle. The charging rate will also vary based on the climatic conditions, affecting the temperature of battery used. It has been identified that charging rate and performance improves significantly when vehicles are charged simultaneously. However, the need for energy during peak charging 
Journal of Electrical Engineering and Automation (EEA) (2021)

Vol.03/ No.01

Pages: 55-64

https://www.irojournals.com/iroeea

DOI: https://doi.org/10.36548/jeea.2021.1.006

time can be compensated with the help of energy storage systems. The investment cost of the solar power is represented by the following equation:

$$
\left\{\begin{array}{c}
p_{i n v}^{\text {sol }}=\sum_{i \in I}\left(T A_{i n s}^{i} \times B_{1} \times B_{2} \times I_{\text {sol }} \times P_{\text {sol }}\right) \\
B_{1}=\theta \times \frac{(1+\theta)^{\delta}}{(1+\theta)^{\delta}-1} \\
B_{2}=\frac{R_{y}}{(1+\theta)^{i}}
\end{array}\right.
$$

Where $p_{i n v}^{s o l}$ denotes the investment without taking into consideration the savage value. The efficiency of hourly rate of the energy storage system can be determined using the following expression:

$$
\omega_{e s}=\frac{\sum_{i \in I}\left(P_{d e s}\right)}{\sum_{i \in I}\left(P_{c e s}\right)}
$$

The operational maintenance cost of the converter can be expressed using the following equations:

$$
\begin{array}{r}
\left.p_{\text {inv }}^{\text {maintenance }}=\sum_{i \in I} T A_{\text {ins }}^{i} \times B_{1} \times B_{2} \times I_{\text {sol }} \times P_{\text {sol }}\right) \\
\left.p_{\text {operation }}^{\text {maintenance }}=\sum_{i \in I} T A_{\text {ins }}^{i} \times B_{1} \times B_{2} \times I_{\text {sol }} \times P_{\text {sol }} \times 365\right)
\end{array}
$$

Hence the network expansion will evaluate the final cost using the following expression

$$
\left.p_{\text {operation }}^{\text {ces }}=\sum_{i \in I} T A_{\text {ins }}^{i} \times P_{\text {des }} \times P_{\text {ces }} \times 365\right)
$$


Journal of Electrical Engineering and Automation (EEA) (2021)

Vol.03/ No.01

Pages: 55-64

https://www.irojournals.com/iroeea

DOI: https://doi.org/10.36548/jeea.2021.1.006

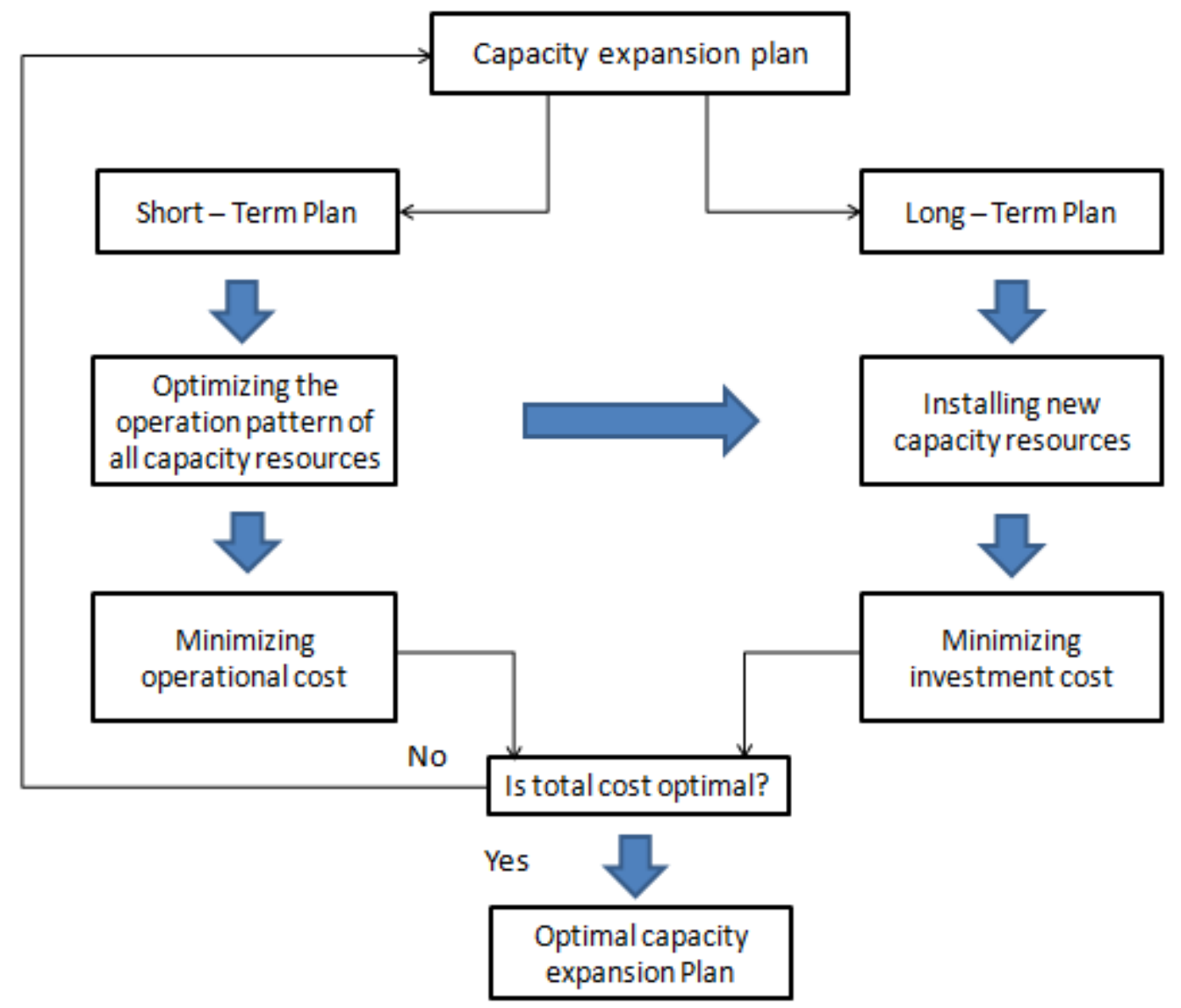

Fig.2. Proposed Methodology Flowchart

\section{Results and Discussion}

In this work we have considered a microgrid that operates on $10 \mathrm{~kW}$ micro turbine, $30 \mathrm{~kW}$ solar panels and $30 \mathrm{~kW}$ wind turbine. Fig.3 shows the planning that has taken place for a period of 5 years. Based on the planning horizon, the capacity resources is equally divided and expanded. 


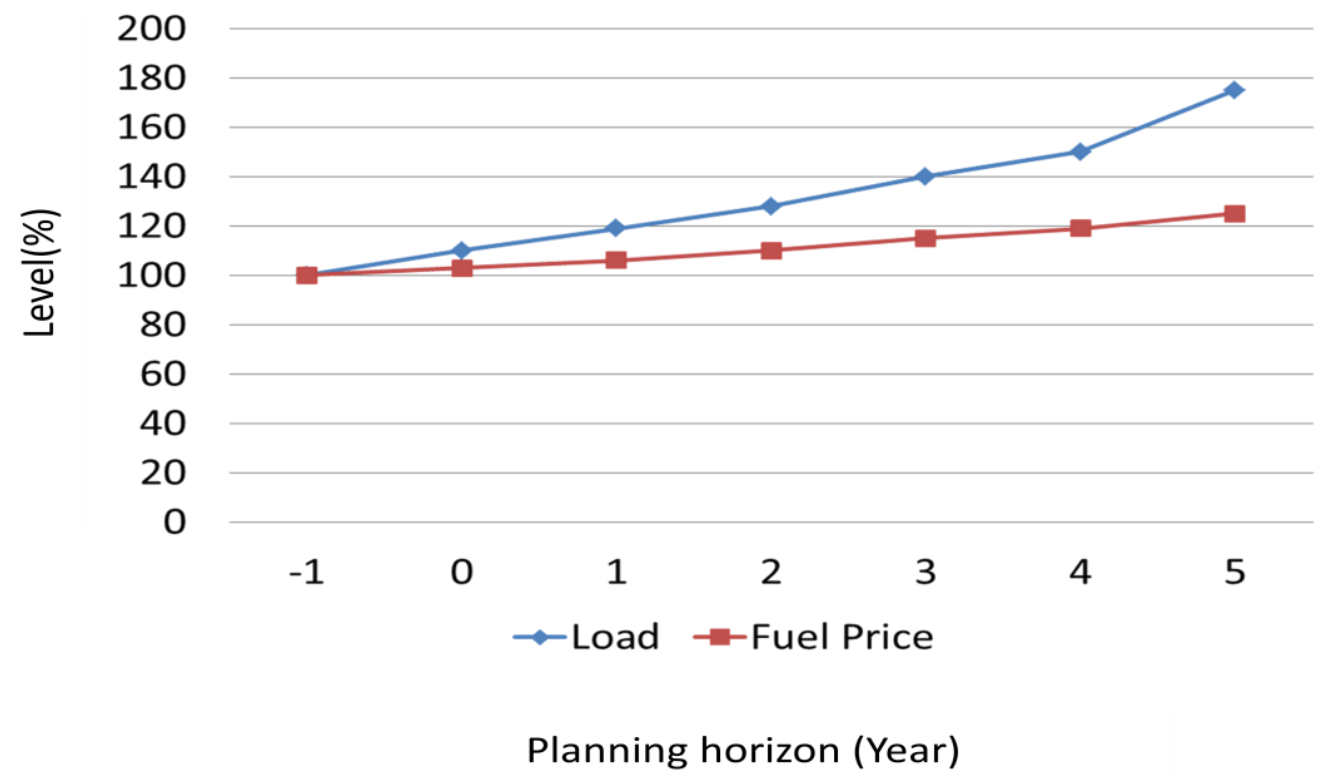

Fig.3. Planning Horizon

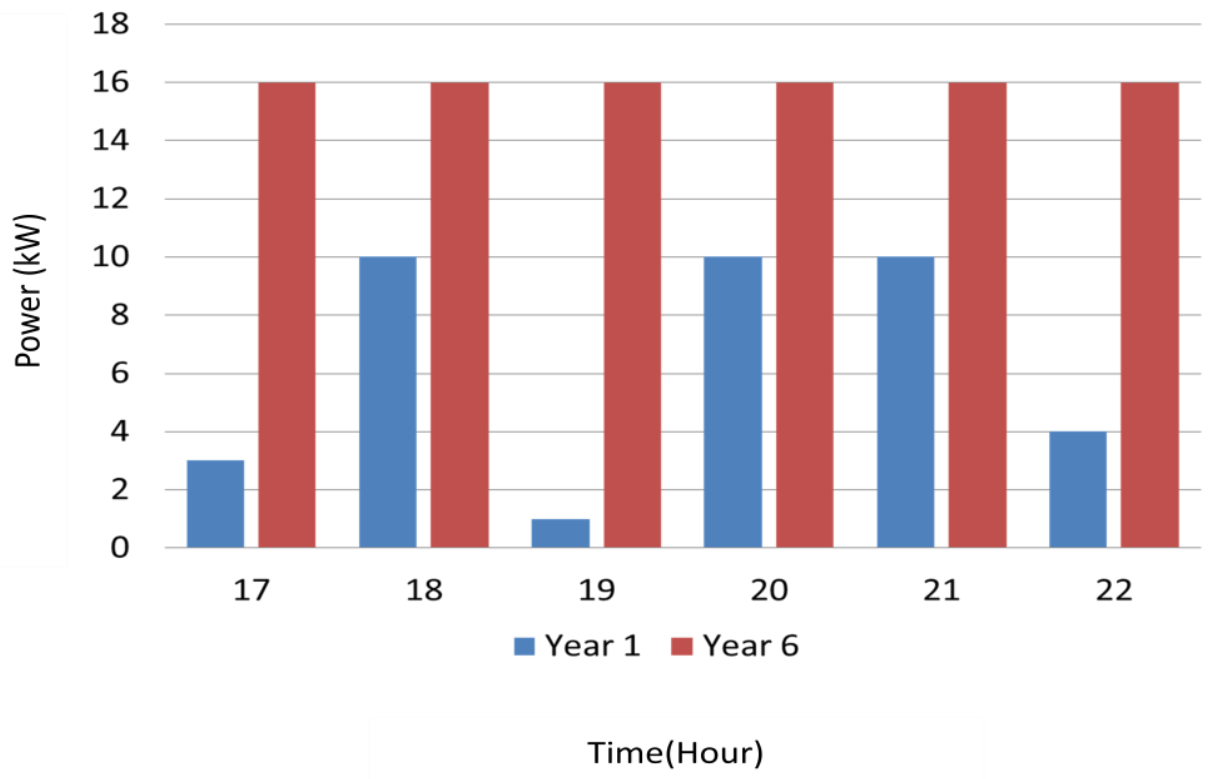

Fig.4. Microturbine operation Timeline

The exchange of power between the upstreen network and the microgrid is represented in Fig.4 for a period of six years. The limit of the $180 \mathrm{~kW}$ is imposed on the upstream network and microgrid. On the other hand, Fig.5 represents the operation of energy storage during the planning horizon. It paves the way to reduced price during peak hours. 


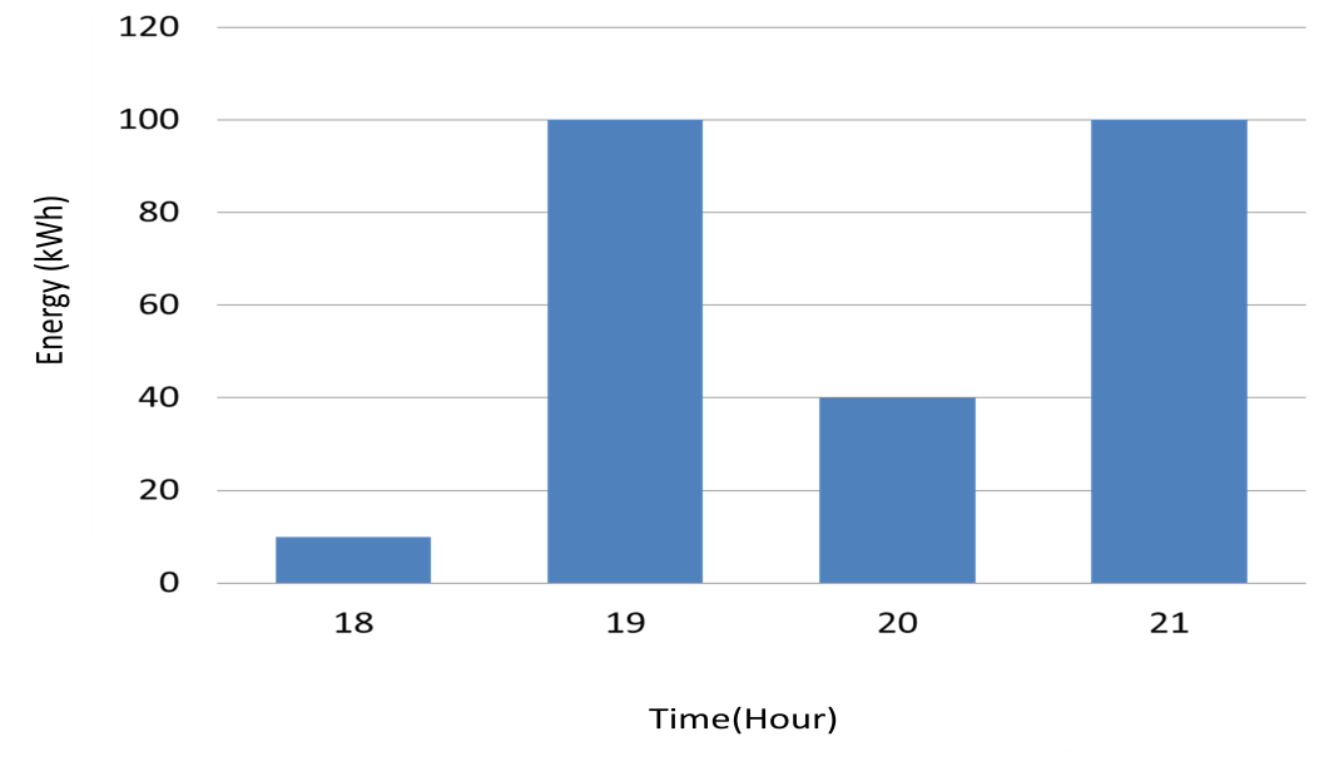

Fig.5. Electric Vehicle Arrival

\section{Conclusion}

In this paper, an advanced model for expanding the capacity of microgrid is proposed. Micro, wind and solar turbine are used to supply the microgrid which in turn is fixed with the upstream grid. The microgrid under test was connected to electric vehicle charging station and energy storage system based on the 6-year expansion planning. Based on the load growth, the capacity resources were built to manage the load growth. The primary objective of the proposed work is to decrease the cost of investment using new capacity resources. Based on the experimental analysis and the results recorded, wind energy is said to be of higher profit when compared to the solar energy profile. Records show that when compared with solar energy, the wind energy expansion is $180 \%$. The micro turbine installed occupies $23 \%$ cost and wind resources occupy $51 \%$ of the total cost. A significant improvement has been observed based on the charging rate and operation of the electric vehicle charging station. It is observed that this methodology decreasing the cost of planning by $30 \%$. It has also been successfully verified that the planning cost increases by $44 \%$ due to variation in parameters like solar and wind energy. 
Journal of Electrical Engineering and Automation (EEA) (2021)

Vol.03/ No.01

Pages: 55-64

https://www.irojournals.com/iroeea

DOI: https://doi.org/10.36548/jeea.2021.1.006

\section{References}

[1] Datta, U., Kalam, A., \& Shi, J. (2019). The Strategies of EV Charge/Discharge Management in Smart Grid Vehicle-to-Everything (V2X) Communication Networks. Advanced Communication and Control Methods for Future Smartgrids, 177.

[2] Zahurul, S., Mariun, N., Grozescu, I. V., Tsuyoshi, H., Mitani, Y., Othman, M. L., ... \& Abidin, I. Z. (2016). Future strategic plan analysis for integrating distributed renewable generation to smart grid through wireless sensor network: Malaysia prospect. Renewable and Sustainable Energy Reviews, 53, 978-992.

[3] Kikusato, H., Mori, K., Yoshizawa, S., Fujimoto, Y., Asano, H., Hayashi, Y., ... \& Suzuki, T. (2018). Electric vehicle charge-discharge management for utilization of photovoltaic by coordination between home and grid energy management systems. IEEE Transactions on Smart Grid, 10(3), 3186-3197.

[4] Bhalaji, N. (2020). EL DAPP-An Electricity Meter Tracking Decentralızed Application. Journal of Electronics, 2(01), 49-71.

[5] Brown, M. A., \& Zhou, S. (2013). Smart-grid policies: an international review. Wiley Interdisciplinary Reviews: Energy and Environment, 2(2), 121-139.

[6] Worighi, I., Maach, A., \& Hafid, A. (2015, December). Modeling a smart grid using objects interaction. In 2015 3rd International Renewable and Sustainable Energy Conference (IRSEC) (pp. 1-6). IEEE.

[7] Shirley, D. R. A. (2014, July). Systematic diagnosis of power switches. In 2014 International Conference on Embedded Systems (ICES) (pp. 32-34). IEEE.

[8] Dileep, G. (2020). A survey on smart grid technologies and applications. Renewable Energy, 146, 2589-2625.

[9] Vandael, S., Boucké, N., Holvoet, T., \& Deconinck, G. (2010, May). Decentralized demand side management of plug-in hybrid vehicles in a smart grid. In Proceedings of the first international workshop on agent technologies for energy systems (ATES 2010) (pp. 67-74).

[10] Wade, N. S., Taylor, P. C., Lang, P. D., \& Jones, P. R. (2010). Evaluating the benefits of an electrical energy storage system in a future smart grid. Energy policy, 38(11), 7180-7188. 
Journal of Electrical Engineering and Automation (EEA) (2021)

Vol.03/ No.01

Pages: 55-64

https://www.irojournals.com/iroeea

DOI: $\underline{\text { https://doi.org/10.36548/jeea.2021.1.006 }}$

[11] Saad, W., Han, Z., Poor, H. V., \& Basar, T. (2012). Game-theoretic methods for the smart grid: An overview of microgrid systems, demand-side management, and smart grid communications. IEEE Signal Processing Magazine, 29(5), 86-105.

[12] Mugunthan, S., \& Vijayakumar, T. (2019). Review on IoT based smart grid architecture implementations. $j$ Electric Eng Autom, 1(1), 12-20.

[13] Haoxiang, W., \& Smys, S. (2020). Secure and Optimized Cloud-Based CyberPhysical Systems with Memory-Aware Scheduling Scheme. Journal of trends in Computer Science and Smart technology (TCSST), 2(03), 141-147. 